\title{
Experimental and Numerical Behavior of Plain Hybrid Fiber Metal Laminate Composites
}

\author{
${ }^{1}$ Aiea A. Elhabak, ${ }^{2}$ Mostafa Shazly, ${ }^{1}$ Tarek A. Osman and ${ }^{1}$ Aly A. Khattab \\ ${ }^{1}$ Department of Mechanical Design and Production Engineering, Faculty of Engineering, \\ Cairo University, Giza, Egypt \\ ${ }^{2}$ Department of Mechanical Engineering, Faculty of Engineering, The British University in Egypt, \\ El Sherouk City, 11873 Cairo, Egypt
}

\begin{abstract}
This study presents an investigation to themechanical properties of FML components under static axial and bending loads. Two types of Fiber Metal Laminates (FMLs), namely, FML 1 and 2 were considered in the present research. FML1 contains 4 layers of laminated glass/epoxy laminate while FML 2 contains two aramid fiber laminates that replaced the glass/epoxy laminates and adjacent to the inner metal layer. Experimental stiffness and strength are discussed and compared with the theoretical values. Under bending loads, two different end conditions are considered, free and fixed and the results both ends were compared. Finite Element Analysis (FEA) was conducted to evaluate the FML properties and failure mode and compare them with the experimental results. The outcome of the present study indicated that the mechanical properties of the FML structures which named FML 2 were slightly higher than FML 1. Failure patterns were also, observed and identified.
\end{abstract}

Key words: Woven e-Glass, Kevlar fabric, epoxy, hybrid aluminum composite, tensile, flexural, finite element analysis

\section{INTRODUCTION}

High strength aluminum sheets have attracted a new type of hybrid composite structures based on alternate Fiber Metal Laminates (FML). Many researchers have tried to understand FML properties and design parameters. These parameters can be summarized in a few elements such asmetal thickness, metal type, surface treatment of metal layers, geometry and fiber reinforced types, fiber orientations and manufacturing process (Vlot and Gunnink, 2001; Salve et al., 2016). Extensive theoretical and numerical analysis to determine the lamina properties has been done earlier (Ochoa and Reddy, 1992). Glass Laminate Aluminum Reinforced Epoxy (GLARE) plates belong to fibrous metal chip segments and are made up of alternating layers of fiberglass reinforced materials and aluminum sheets. Initially, GLARE was developed for aerospace applications as an improvement of Aramid Fiber Reinforced Aluminum Laminate (ARALL) with advanced fiber glass (Esfandiar et al., 2011; Swaminathan et al, 2016). GLARE had been introduced due to the good compressive properties of the glass which provide better flexibility in loading of GLARE than ARALL due to the poor behavior of Aramid fibers under compressive loading. GLARE is currently used in many parts in aerospace applications by tailoring its properties by choosing the proper fiber and matrix. The advantages and disadvantages of the different fibers of metal fiber sheet structures were discussed previously by Akkerman (2005).

The aim of studying the material properties is much greater when different types of fibers are incorporated into the same resin matrix. To study the potential of these materials, in this research the samples are prepared with glass/epoxy laminates and Kevlar/epoxy laminates. Kevlar fibers are characterized by special strength and stiffness as compared to the glass fiber. It is known that, the main deficiency of Kevlar fiber is that the low compressive strength and high cost. Therefore, this research is dedicated to owning a large benefit of fiberglass and Kevlar fibers.

\section{MATERIALS AND METHODS}

\section{Experimental work}

Materials and specimen preparations: FMLs used in the present research consist of successive layers of composite laminates and a monolithic metal. The metal layers used are thin aluminum sheets of 2024-T3 with a thickness of $0.4 \mathrm{~mm}$. The composite laminates composed

Corresponding Author: Aiea A. Elhabak, Department of Mechanical Design and Production Engineering, Faculty of Engineering, Cairo University, Giza, Egypt 
Table 1: Relative content and density of the fabricated fiber metal laminates

\begin{tabular}{lcccccc}
\hline FML type (Layup) & Glass (\%) & Kevlar (\%) & Epoxy (\%) & $\mathrm{Al}(\%)$ & Laminated density (\%) & FML density $(\%)$ \\
\hline FML1 Al/G/G/Al/G/G/Al) & 10.2 & --- & 56.5 & 33.3 & 1.38 & 1.817 \\
FML2 $(\mathrm{Al} / \mathrm{G} / \mathrm{K} / \mathrm{Al} / \mathrm{K} / \mathrm{G} / \mathrm{Al})$ & 11.12 & 6.78 & 42.1 & 40 & 1.372 & 1.899 \\
\hline
\end{tabular}

of woven e-Glass mats (EBX600) or Kevlar, Twaron type) fabric impregnated in epoxy resin (EPOLAM2017 resin with EPOLAM2018 hardener).

The goal of the manufacturing processis to obtain two familiar types of FML structures. FML 1 stacked in the following configuration: $\mathrm{Al} / \mathrm{G} / \mathrm{G} / \mathrm{Al} / \mathrm{G} / \mathrm{G} / \mathrm{Al}$. While FML 2 which is made of Glass $(\mathrm{G})$ and Kevlar $(\mathrm{K})$ fiber reinforcement has stacking the following sequence $\mathrm{Al} / \mathrm{G} / \mathrm{K} / \mathrm{Al} / \mathrm{K} / \mathrm{G} / \mathrm{Al}$.

FML plates are cured at $600^{\circ} \mathrm{C}$ for 240 min and then furnace cooled to room temperature before placing the munder vacuum pressure 0.25 bar for $24 \mathrm{~h}$. A hydraulic shearing machine isused to cut the samples with dimensions of $200 \mathrm{~mm}$ length and $20 \mathrm{~mm}$ width. The fraction of size for each metal, fiber and matrix is also, calculated and listed in Table 1 with the composite laminated density as well as the FML density.

Testing procedure: In order to obtain the characteristics of FML specimens, tensile and bending tests (3-point bending) are performed for unnotched samples. Tensile and bending tests are carried out on a universal test apparatus with $10 \mathrm{kN}$, Amsler testing machine works with four load ranges with a maximum capacity of $100 \mathrm{kN}$ at the Materials and Testing Laboratory, Faculty of Engineering, Cairo University. Tests are conductedwith a crosshead stroke rate of $2.5 \mathrm{~mm} / \mathrm{min}$ at room temperature. The specimen's deformation in both test are measured using a digital camera to the deformation of each test and the corresponding force (measured by the machine). The fracture surface of each test conditions was observed optically instantaneously. Tensile tests are conducted according to ASTM D3039-14 standard. Experimental data obtained are then used to determine the elastic modulus, strength and failure pattern.

The bending test is used to determine bending stiffness and strength. All bending samples are tested according to ASTM D790-15. Both simply supported and fixed-fixed end conditions are adopted in the present research.

Finite element modeling: Finite element modeling is conducted, here, to verify and explain the experimental results obtained hereafter. The non-linear finite element solver ABAQUS/Explicit is used in modeling the tensile and bending specimens reported in the experimental work. The simulations time is chosen such that the effect of inertia forces are minimum. The Glass and Kevlar
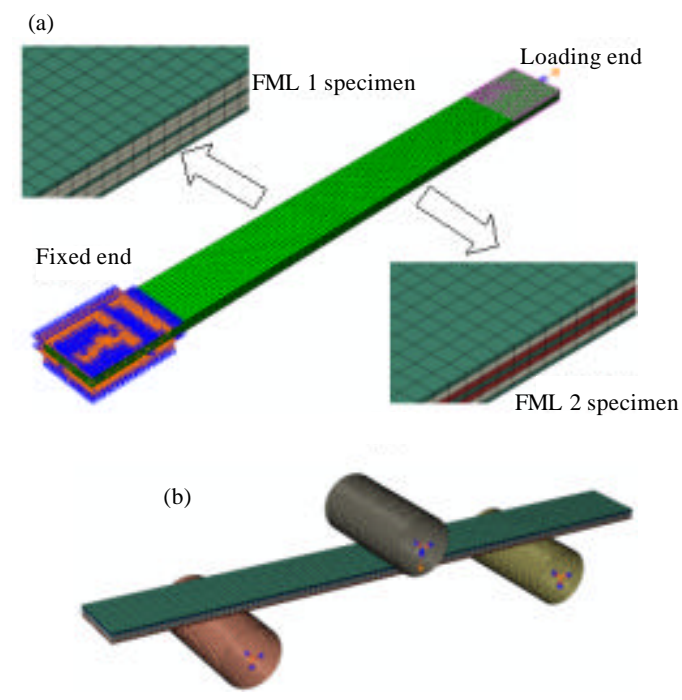

Fig. 1: Finite element for: a) Tensile and b) Bending configurations

laminates are modeled using continuum shell elements with a linear elastic, orthotropic material model where each laminate is modeled with one element through thickness as shown in Fig. 1 for both tensile and bending configurations. Table 2 lists the elastic properties used in the present finite element analysis. The number and size of shell elements can be tailored to provide accurate results at convenient computational cost. Hashin's criterion (Mallick, 2007) is used to model the onset of damage initiation within the laminates based on fiber and matrix strengths separately both in tension and in compression. For the Glass and Kevlar fibers laminate used in the present analysis, fiber strength, matrix strength and the longitudinal and transverse shear strength of a unidirectional composite are given in Table 3. After the damage initiation, damage evolution is based on total energy dissipated after damage initiation and is modeled as a linear softening stress displacement relationship. The aluminum alloy A12024-T3 used in the present research is molded using isotropic plasticity model following von Mises yield criterion with the flow stress-plastic strain relationship is given in Table 4 (Ergun et al., 2018). The bonding between laminates is assumed to be perfect and modeled using tie constraint. Displacement boundary conditions are applied at one end of the sample over a length equals to the grip length while the other end is kept fixed in the tensile experiments. Reaction forces are summed at the specimen end and 
Table 2: Elastic properties of glass and Kevlar epoxy laminates

\begin{tabular}{lllllllll}
\hline Variables & $\mathrm{E}_{1}(\mathrm{MPa})$ & $\mathrm{E}_{2}(\mathrm{MPa})$ & $\mathrm{E}_{3}(\mathrm{MPa})$ & $\boldsymbol{\bullet}_{12}$ & $\boldsymbol{\bullet}_{23}$ & $\mathrm{G}_{12}(\mathrm{MPa})$ & $\mathrm{G}_{13}(\mathrm{MPa})$ & $\mathrm{G}_{23}(\mathrm{MPa})$ \\
\hline Glass & 14390 & 14390 & 5043 & 0.076 & 0.25 & 1960 & 1953 & 1953 \\
Kevlar & 22200 & 22200 & 5239 & 0.061 & 0.311 & 2227 & 2183 & 2183 \\
\hline
\end{tabular}

Table 3: Laminate's strength for both glass and Kevlar epoxy specimens

\begin{tabular}{lcccccc} 
Variables & $\begin{array}{c}\text { Longitudinal tensile } \\
\text { strength (MPa) }\end{array}$ & $\begin{array}{c}\text { Longitudinal compressive } \\
\text { strength (MPa) }\end{array}$ & $\begin{array}{c}\text { Transverse tensile } \\
\text { strength (MPa) }\end{array}$ & $\begin{array}{c}\text { Transverse compressive } \\
\text { strength (MPa) }\end{array}$ & $\begin{array}{c}\text { Longitudinal shear } \\
\text { strength (MPa) }\end{array}$ & $\begin{array}{c}\text { Longitudinal shear } \\
\text { strength (MPa) }\end{array}$ \\
\hline Glass & 404.5 & 325.6 & 404.5 & 325.6 & 36.5 & 36.5 \\
Kevlar & 346.3 & 321.2 & 346.3 & 321.2 & 36 & 36 \\
\hline
\end{tabular}

Table 4: Flow stress plastic strain of A12024-T3

\begin{tabular}{lc}
\hline Flow stress (MPa) & Plastic strain (\%) \\
\hline 294 & 0.0 \\
335 & 1.1 \\
362 & 2.2 \\
381 & 3.2 \\
399 & 4.4 \\
415 & 5.5 \\
430 & 6.7 \\
443 & 7.8 \\
459 & 9.2 \\
469 & 10.1 \\
480 & 11.2 \\
\hline
\end{tabular}

plotted against the end displacement. The bending rollers are modeled as rigid parts where the support rollers are fixed and displacement is applied at the central roller.

\section{RESULTS AND DISCUSSION}

Theoretical properties: A broad theoretical analyses were carried out to determine the characteristics of the composite laminate by several investigators. The mechanical properties of the composite layer have been explained in terms of constituents with simple formulas on the assumption that the layer is transversely isotropic with a balanced reinforcement of woven fabrics (Akkerman, 2005). FML properties depend primarily on the configured properties as well as on the relative size segment. Therefore, the rule of mixture, in this research, is the basic method used to determine the stiffness and strength of the FML structures. The strength and stiffness of polymer composite laminate have been discussed and then the hybrid rule of the mixture can be applied to determine the properties of FML (Van Rooijen et al., 2004; Monika and Mania, 2015).

The theoretical tensile strength is 326.8 and 334.5 MPa for samples of FML 1 and FML 2, respectively. Also, the elastic moduli for the same samples are 20.6 and 29.2 GPa, respectively. One can observe that the irrespective change of the composite laminate type (Glass and Kevlar) with the change of ultimate strength seems to be insignificant. However, a great influence is cleared strongly on the modulus of elasticity for the two samples.

Tensile results: The purpose of tensile testing is to determine the basic mechanical properties under axial load

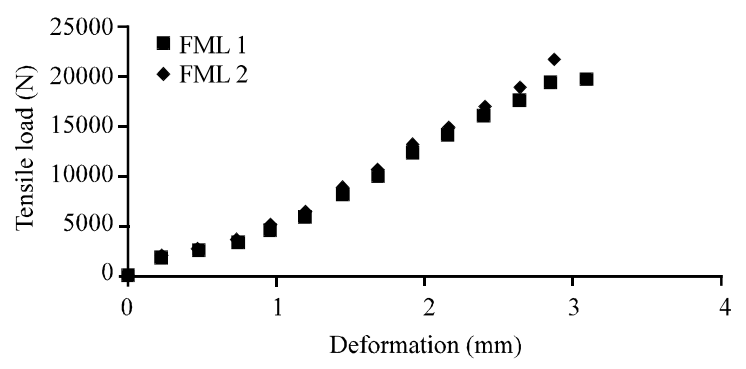

Fig. 2: Tensile load-deformation curve for FML 1 and 2 specimens

such as strength and stiffness as well as damage initiation and propagation. Figure 2 shows the tensile load-deformation results of the unnotched specimens. The experimental tensile strength of the FML 1 samples is found to be 318.2 and $335.8 \mathrm{MPa}$ for FML 2. The linear relationship between load and deformation reveals the experimental tensile elastic modulus of $19.1 \mathrm{GPa}$ for FML 1 and $23.98 \mathrm{GPa}$ for FML 2. The tensile data show that the average tensile stiffness $(\mathrm{K}=\mathrm{F} / \bullet)$ is $13.8 \mathrm{kN} / \mathrm{mm}$ and $11.55 \mathrm{kN} / \mathrm{mm}$ for FML 1 and 2, respectively.

The experimental results show that the introduction of the Kevlar layerinstead of the glass layer positively affects the material strength and negatively affects the stiffness of the samples. Experimental data as well as the theoretical values show that the elastic modulus of FML 2 samples is higher than the equivalent values of FML 1. This is due to the difference in stiffness between glass fibers, $\mathrm{E}=72 \mathrm{GPa}$ and Kevlar fibers, $\mathrm{E}=124 \mathrm{MPa}$.

Flexural results: Figure 3 shows the flexural load versus beam deflection for un-notched specimens of materials 1 and FML 2. The bending modulus of elasticity can be determined from experimentaldata in addition to bending stiffness $(\mathrm{K}=\mathrm{F} / \bullet)$. The bending tensile strength is 597.5 MPa for samples of FML 1 and 349.3 MPa for FML 2. The modulus in bending is 36.87 and $28.67 \mathrm{GPa}$ for FML 1 and 2 , respectively. Also, the specimen's bending stiffness $(\mathrm{K})$ is $72.2 \mathrm{~N} / \mathrm{mm}$ for FML1 and $25.5 \mathrm{~N} / \mathrm{mm}$ for FML2. Current results show that FML 1 samples are more stiffthan the FML 2 samples. 


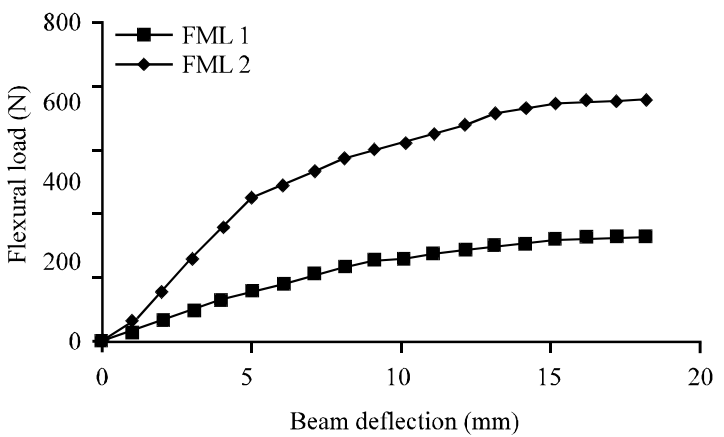

Fig. 3: Flexural trends of un-notched specimens of FML 1 and 2
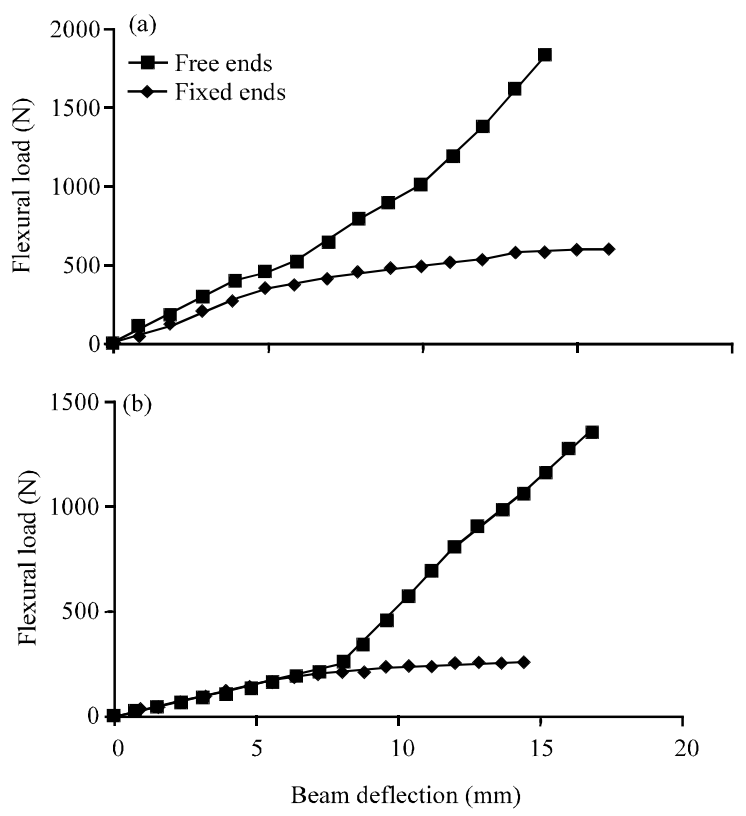

Fig. 4: Flexural load for different end conditions: a) FML 1 and b) FML 2

To understand the flexural response of the FML under combined tensile and bending loads, the previous bend tests are conducted with fixed-ends conditions. Figure 4 presents the flexural load versus deflection for both end conditions. The initial bending stiffness $(\mathrm{K})$ arefoundto be $93 \mathrm{~N} / \mathrm{mm}$ for FML 1 samples and $26 \mathrm{~N} / \mathrm{mm}$ for FML 2 samples. The bending results of the free or fixed endings show that the initial bending stiffness of FML 1 and 2 has almost the sameas shown in Fig. 4. Flexural results reveal the initial bendingtrend, generally, independent of the end condition, especially, in the elastic range. The experimental results show that the elastic distortion of FML 2 (about $10 \mathrm{~mm}$ ) is twice the value corresponding to the FML1 samples (about $5 \mathrm{~mm}$ ).

The bending strength to tensile strength ratios are found to be 1.878 and 1.041 for FML 1 and 2 samples, (a)
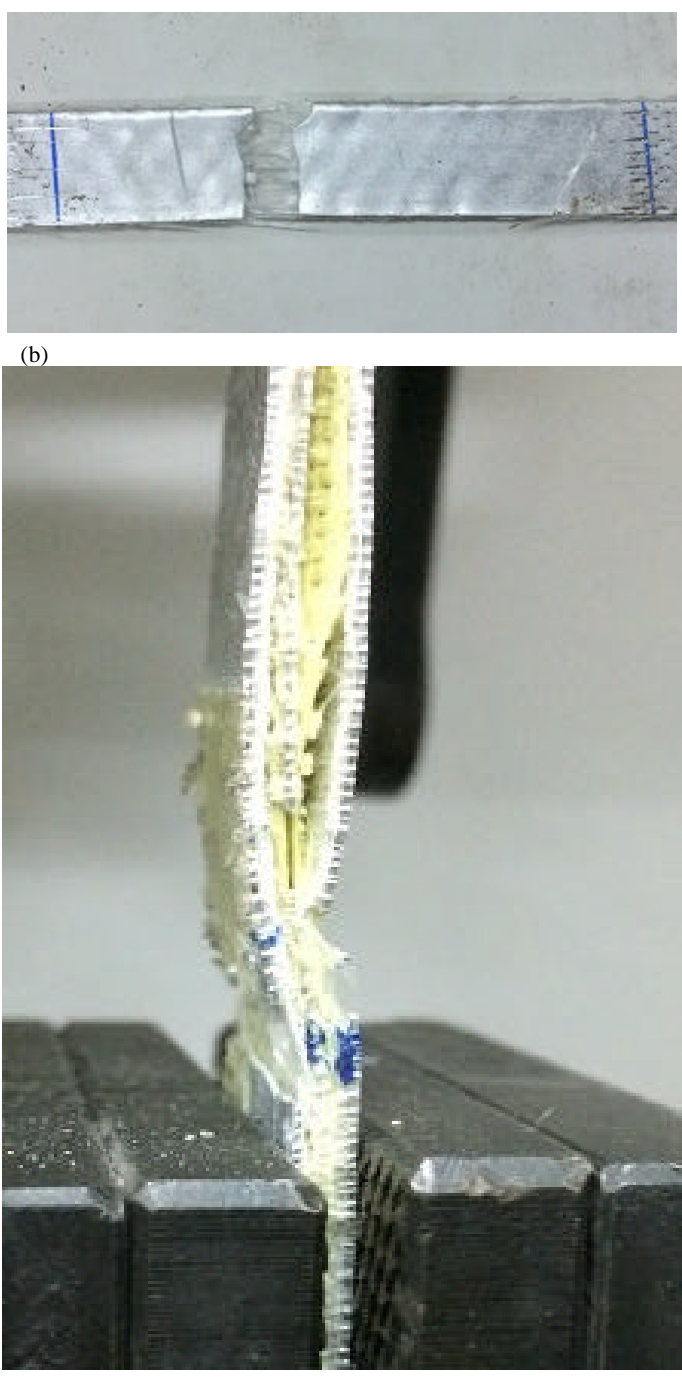

Fig. 5: Tensile fracture for: a) FML 1 and b) FML 2

respectively. Similarly, the corresponding stiffness are approximately 1.932 and 1.196 . This means that the GLARE samples, FML 1 have more rigidity than the corresponding samples of FML 2, containing Kevlar laminates.

Fracture analysis: Figure 5 shows the fracture surface of the tensile test specimens. The net tensile fracture was observed clearly on the aluminum layers attendant in the fiber breaking of the laminates. Visual observation shows that there is no any delamination or matrix crack on the tensile test specimens of FML 1 materials. Fracture of FML 2 specimens of occurs as a net tensile failure accompanied with the separation of the Kevlar fabric layers from the interior aluminum layer while the glass laminate still in contact with the outer aluminum layers. 
Bending tests show that the tensile fracture occurs in the outer aluminum layer at the tensile side of the unnotched specimens irrespective the end condition of the bending test as shown in Fig. 6. In contrast, the tested specimens of FML 2 were flexible and the failure surface some times disappeared.

Finite elements results: The tensile load-displacement curves for FML 1 and 2 samples are shown in Fig. 7-9.

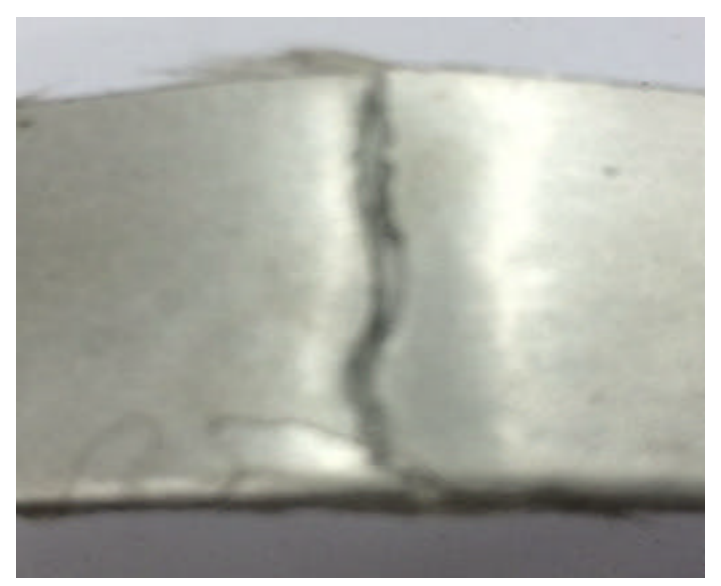

Fig. 6: Fracture surface under bending loadfor both tested FMLs specimens, respectively. The errors in this case compared to the experimental values are $3.6 \%$ for FML 1 and $7 \%$ for FML 2. The corresponding failure strainsare found to be 1.6 and $1.22 \%$ for both FML 1 and 2, respectively. However, the corresponding experimental values are $1.4 \%$ for FML 1 samples and $1.5 \%$ for FML 2. It is known that the FE Model treat the FMLs as

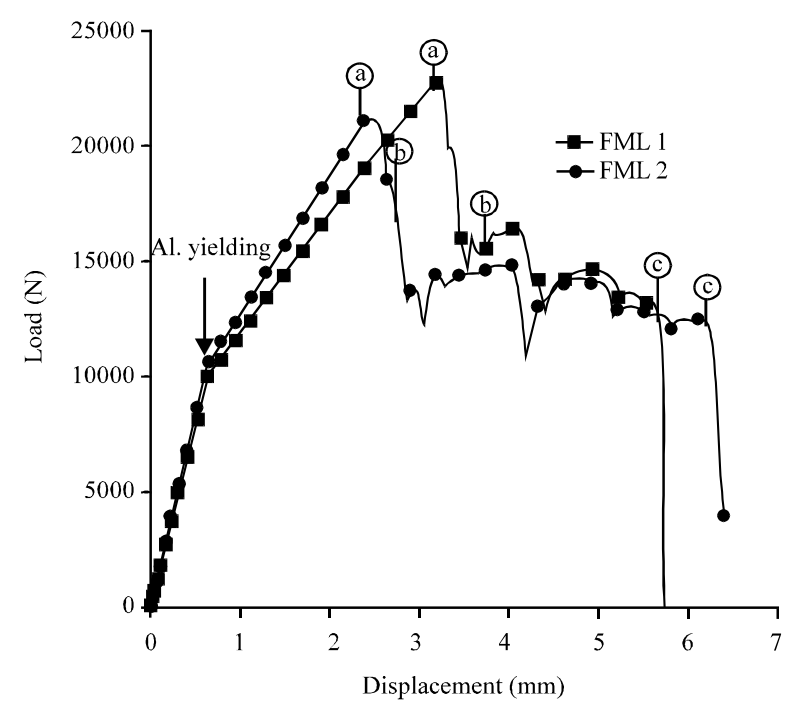

Fig. 7: Tensile load-displacement of FML 1 and 2 samples

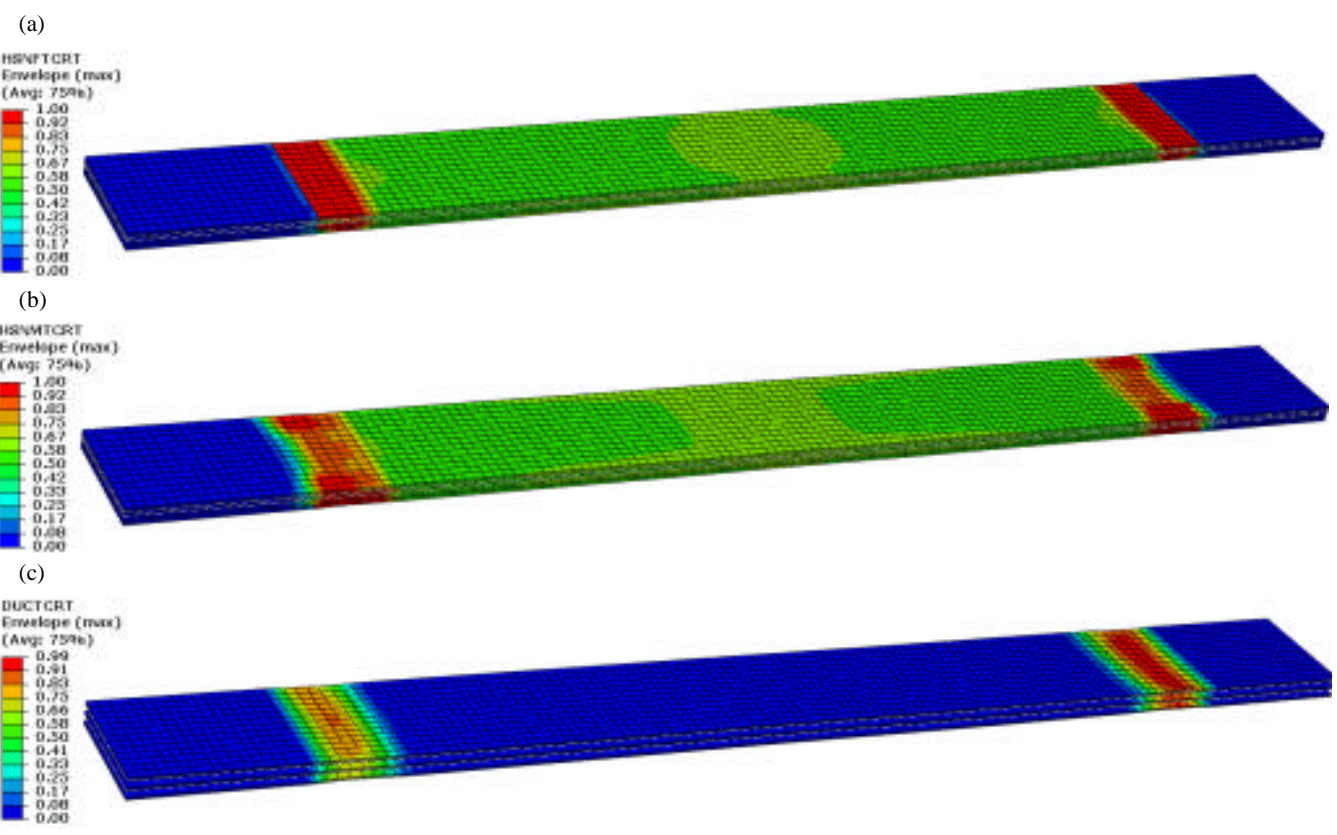

Fig. 8: a-c) Damage evolution during tensile testing of FML 1 specimens. HSNFTCRT and HSNMTCRT refer to Hashin's fibers and matrix tensile failure criteria, respectively. DUCTCRT refers to ductile failure criterion for the aluminum layers 
(a)

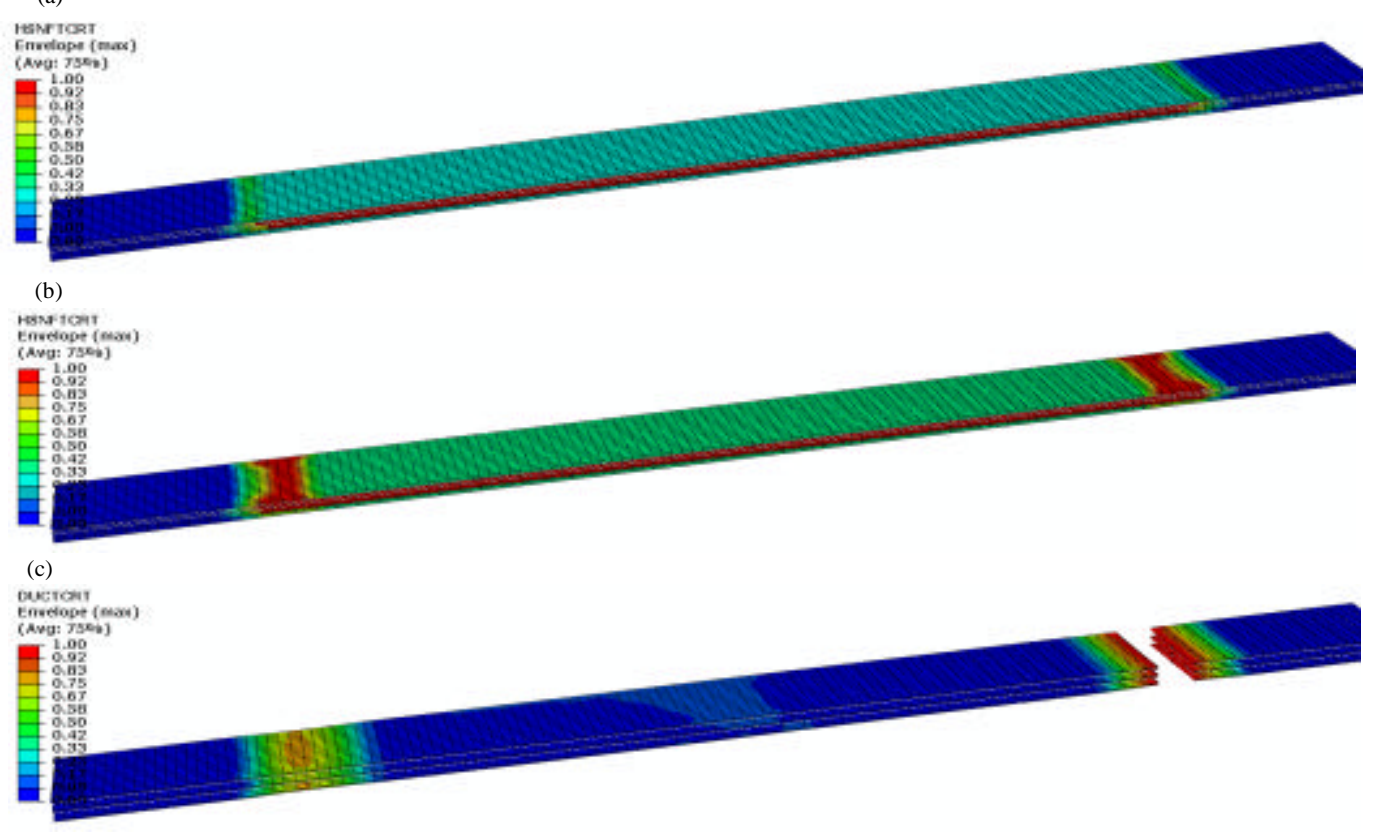

Fig. 9: a-c) Damage evolution during tensile testing of FML 2 specimens. HSNFTCRT and HSNMTCRT refer to Hashin's fibers and matrix tensile failure criteria, respectively. DUCTCRT refers to ductile failure criterion for the aluminum layers

a perfect layer bond adhesion with no residual stresses which may develop during the manufacturing process.

Figure 8 and 9 show the damage evolution in FML 1 and 2 tensile specimens. In both specimens, the change in the slopes correspond to yielding of the aluminum layers. Figure 8a-c are taken at the corresponding marked points (a-c) on the load-displacement curve of Fig. 7. As shown in Fig. 8a, the maximum load is achieved when the glass fiber attain its ultimate tensile strength measured by the Hashin's fiber tensile criterion, followed by matrix failure as shown in Fig. 8b. The total failure is attained when the aluminum attained its ultimate tensile strength as shown by the ductile damage criterion in Fig. 8c. Numerical damage criteria confirm the experimental specimens fracture shown in Fig. 5. Figure 9 shows the damage evolution in FML 2. The damage process starts by fibers failure in the Kevlar layers as shown in Fig. 9a, followed by Glass layers as shown in Fig. 9b. The total failure is attained by the failure of the aluminum layers as shown in Fig. 9c.

Figure 10 and 11 show the bending load versus the corresponding deflection for FML 1 and 2, respectively for different end conditions. Marked points (a-d) represent different damage stages during the bending process presented in Fig. 12-15. Influence of the bending end condition are clearly appeared from point (b)

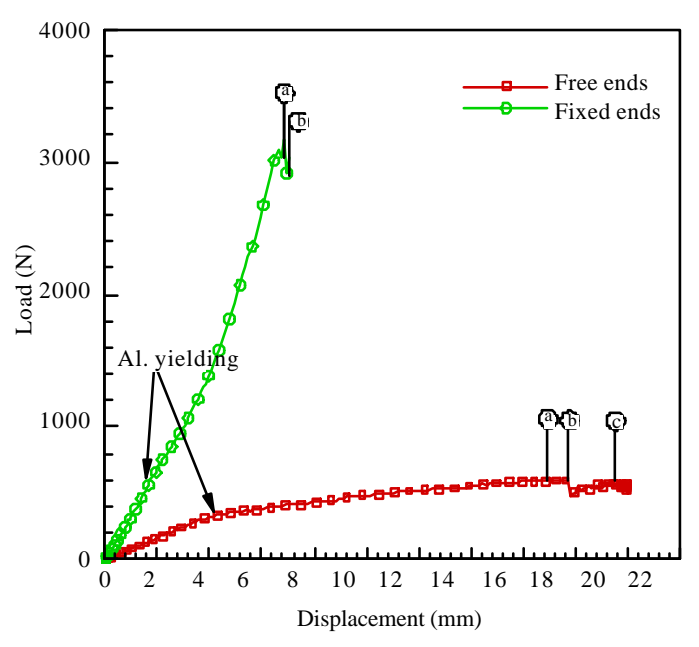

Fig. 10: Bending load-deflection of FML 1

to point (c). From the yield load and the corresponding beam deflection, the bending stiffness is calculated using the equation $\mathrm{K}=\mathrm{P} / \bullet$. The bending stiffness for free end condition are 82.4 and $73.3 \mathrm{~N} / \mathrm{mm}$ for FML 1 and 2, respectively. The corresponding experimental values are 72.2 and $25.5 \mathrm{~N} / \mathrm{mm}$ for both tested materials.

Numerical bending stiffness of FML 1 has value greater than the experimental one by about $12.5 \%$. However, the corresponding value of FML 2 appears to be 


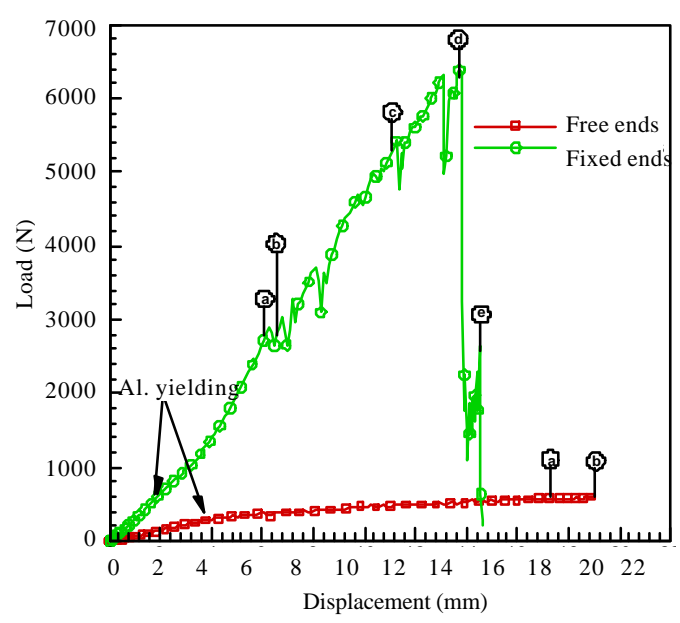

Fig. 11: Bending load-deflection of FML 2 be higher than the experimental one. This is may be due to the difference of the material properties between the glass laminate and the Kevlar laminate which are shown in Table 2 and 3 . One can conclude that the main factor which affect directly on the results is the state of the interfacial bond between the non-identicaltwo successive layers which are used in FML 2. Reference to the tensile fracture as shown in Fig. 5 one can be say that this factor has agreat influence on the numerical results.

Figure 12 and 13 show the damage evolution in bending tests of FML 1 specimens for free and fixed ends conditions, respectively. In reference to Fig. 10,12(a) and (b) show that damage and failure is initiated at the upper glass layer in the form fiber compression before matrix failure at the lower glass layer as shown in Fig. 12(c). For the fixed end conditions, the damage initiates at the fixation lines in the form of fiber failure at the upper glass

(a)

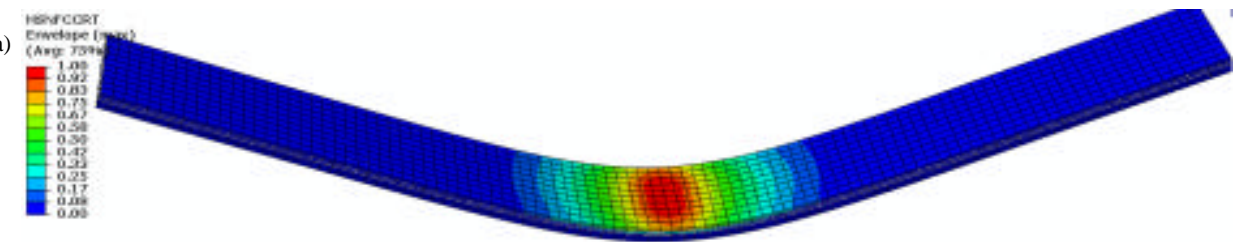

(b)
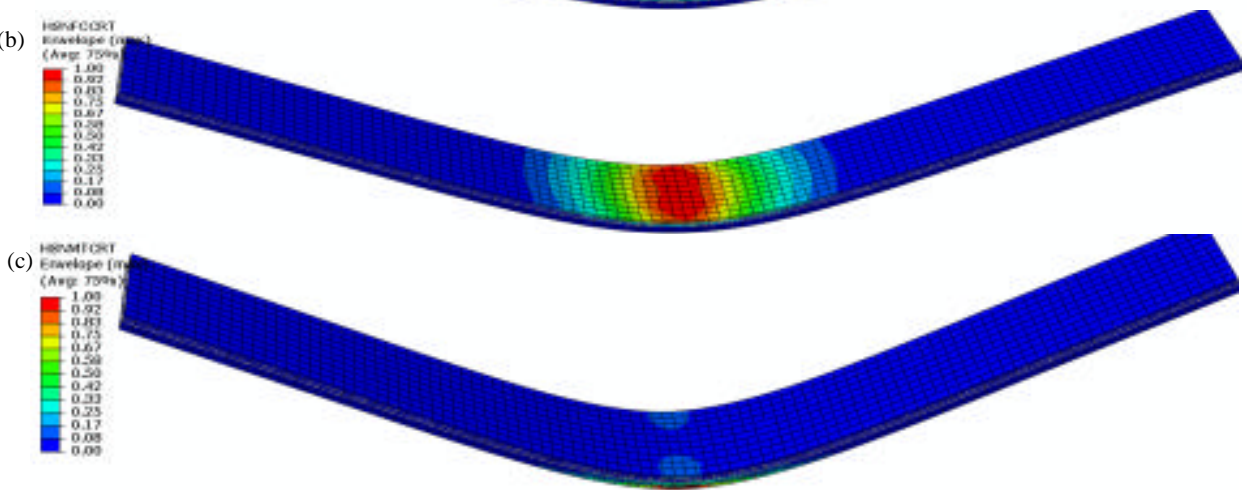

Fig. 12: a-c) Bending damage of free ends FML 1 specimen. HSNFCCRT and HSBMTCRT refer to Hashin's fibers compression and matrix tensile failure criteria, respectively. DUCTCRT refers to ductile failure criterion for the aluminum layer
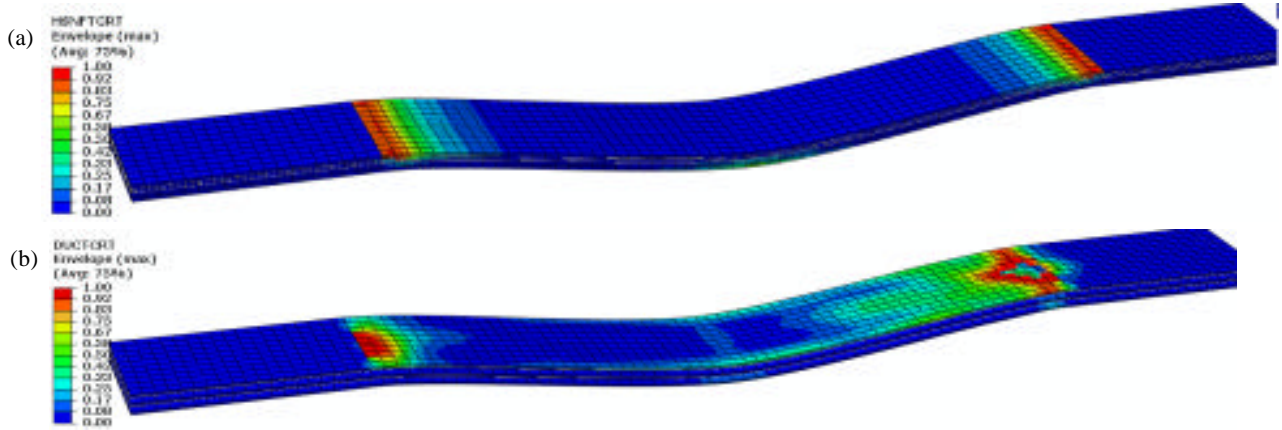

Fig. 13: a, b) Bending damage of fixed ends FML 1 specimen. HSNFTCRT refers to Hashin's fibers failure criterion. DUCTCRT refers to ductile failure criterion for the aluminum layer 


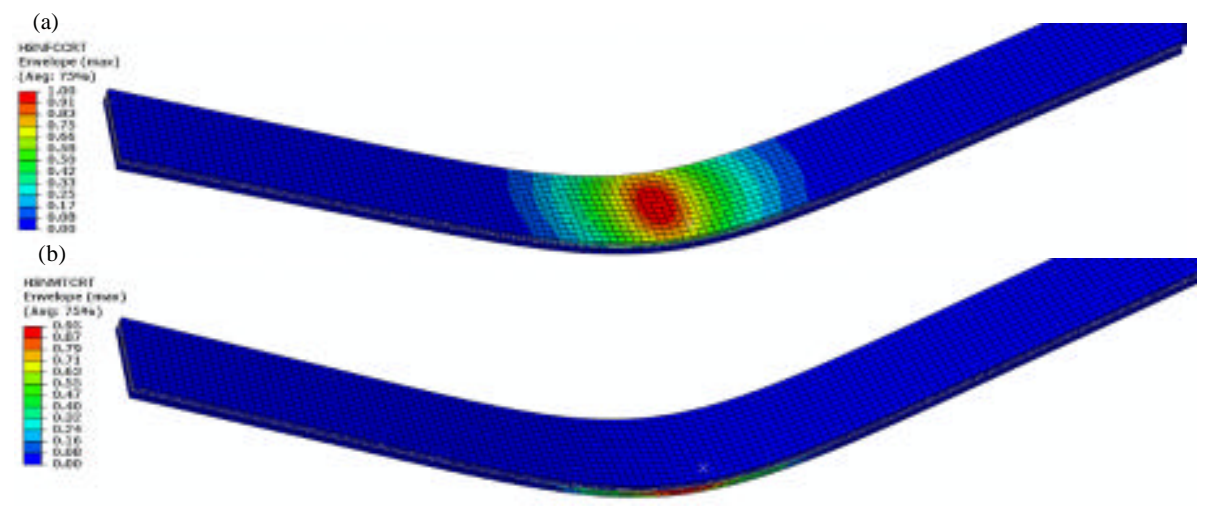

Fig. 14: a and b) Bending damage of free ends FML 2 specimen. HSNFCCRT and HSBMTCRT refer to Hashin's fibers compression and matrix tensile failure criteria, respectively

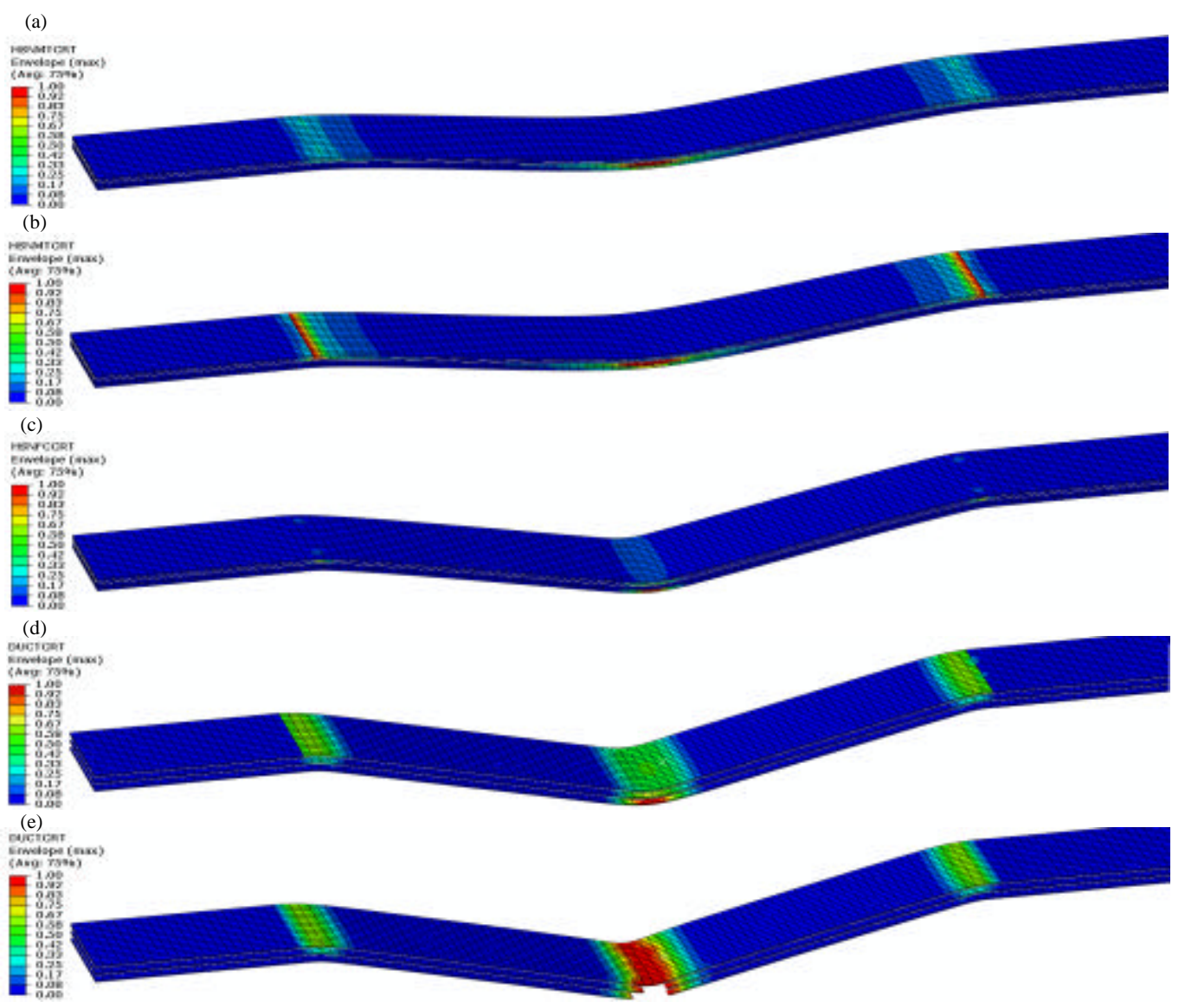

Fig. 15: a-e) Bending damage of fixed ends FML 2 specimen. HSNFCCRT and HSNMTCRT refer to Hashin's fibers compression failure and matrix tensile failure criterion, respectively. DUCTCRT refers to ductile failure criterion for the aluminum layers

layer as shown in Fig. 13a. The total failure is attained at the upper aluminum layer as shown in Fig. 12b. Figure 14 shows the damage evolution during the bending of the FML 2 specimen with free ends. Similar to FML1 specimen, the failure occurs by fiber compression at the upper glass layer and matrix tensile failure at the lower glass layer. For the fixed conditions shown in Fig. 15, the damage initiates at the lower Kevlar layer by matrix 


\begin{tabular}{llll}
\multicolumn{4}{l}{ Table 5: Summary of the material property as obtained experimentally } \\
\hline Properties & Units & FML1 & FML2 \\
\hline Density $(\cdot)$ & $\mathrm{g} / \mathrm{cm}^{3}$ & 1.817 & 1.899 \\
Bending to tensile stress $\left(\cdot \bullet_{\mathrm{t}} \cdot \bullet_{\mathrm{b}}\right)$ & - & 1.87 & 1.04 \\
Bending to tensile stiffness $\left(\mathrm{E}_{\mathrm{t}} / \mathrm{E}_{\mathrm{b}}\right)$ & - & 1.93 & 1.19 \\
Specific tensile stress $\left(\cdot \bullet_{\mathrm{t}} / \bullet\right)$ & $\mathrm{MPa} \cdot \mathrm{cm}^{3} / \mathrm{g}$ & 175.1 & 176.8 \\
Specific tensile stiffness $\left(\mathrm{E}_{\mathrm{t}} / \bullet\right)$ & $\mathrm{MPa} \cdot \mathrm{cm}^{3} / \mathrm{g}$ & 10.51 & 12.628 \\
Specific bending stress $\left(\cdot{ }_{\mathrm{b}} / \bullet\right)$ & $\mathrm{MPa} \cdot \mathrm{cm}^{3} / \mathrm{g}$ & 328.84 & 184.04 \\
Specific bending stiffness $\left(\mathrm{E}_{\mathrm{b}} / \bullet\right)$ & $\mathrm{MPa} \cdot \mathrm{cm}^{3} / \mathrm{g}$ & 20.29 & 15.097 \\
Bending stiffness $\left(\mathrm{K}_{\mathrm{b}}\right)$ & $\mathrm{N} / \mathrm{mm}$ & 72.2 & 25.5 \\
Tensile stiffness $\left(\mathrm{K}_{t}\right)$ & $\mathrm{N} / \mathrm{mm}$ & 13.8 & 11.55 \\
\hline
\end{tabular}

tension as shown in Fig. 15a, b, followed by fiber failure by compression in the lower Glass layer as shown in Fig. 15c. The total failure attained by the failure of the aluminum layers shown in Fig. 15d, e (Table 5).

\section{CONCLUSION}

This study presented data of the tensile and bending characteristics of two FML composites and how these properties are affected by changing the fiber type. The experimental results revealed that replacing the glass laminates with Kevlar laminates around the interior aluminum layer positively affected the elastic material property but negatively affected the stiffness of the samples. Typically, a fiber breaking and pull out failure occurs for each of the FML materials at the loading area for all specimens. Separation occurred between the Kevlar layers and the internal aluminum layer while no separation observed between the glass layer and the outer aluminum layers.

The finite element results are verified against the obtained experimental results. The finite element results presented the sequence of damage initiation and failure propagation under different testing conditions. The data obtained for FML samples can be summarized in order to illustrate the effect of Kevlar laminates added to glass laminates on FML strength and stiffness.

\section{REFERENCES}

Akkerman, R., 2005. Laminate mechanics for balanced woven fabrics. Compos. Part B. Eng., 37: 108-116.

Ergun, H., B.M. Liaw and F. Delale, 2018. Experimental-theoretical predictions of stress-strain curves of Glare fiber metal laminates. J. Compos. Mater., 52: 109-121.

Esfandiar, H., S. Daneshmand and M. Mondali, 2011. Analysis of elastic-plastic behavior of fiber metal laminates subjected to in-plane tensile loading. Intl. J. Adv. Des. Manuf. Technol., 5: 61-69.

Mallick, P.K., 2007. Fiber-Reinforced Composites: Materials, Manufacturing and Design. 3rd Edn., CRC Press, Boca Raton, Florida, USA., ISBN-13:978-1-4200-0598-1, Pages: 619.

Monika, K. and R.J. Mania, 2015. Analytical and experimental determination of FML stiffness and strength properties. Mech. Mech. Eng., 19: 141-159.

Ochoa, O.O. and J.N. Reddy, 1992. Finite Element Analysis of Composite Laminates. Springer, Amsterdam, Netherlands, ISBN:978-0-7923-1125-6, Pages: 213.

Salve, A., R. Kulkarni and A. Mache, 2016. A review: Fiber Metal Laminates (FML's)-Manufacturing, test methods and numerical modeling. Intl. J. Eng. Technol. Sci., 6: 71-84.

Swaminathan, R., K.N. Prabahar, M. Syed Abuthahir and V. Sidharth, 2016. Design and analyze the characteristics of hybrid fiber metal laminate. Intl. J. Innovative Res. Sci. Eng. Technol., 5: 7932-7938.

Van Rooijen, R., J. Sinke, T.J. De Vries and S. Van Der Zwaag, 2004. Property optimisation in fibre metal laminates. Appl. Compos. Mater., 11: 63-76.

Vlot, A. and J.W. Gunnink, 2001. Fiber Metal Laminates: An Introduction. Springer, Berlin, Garmany, ISBN:9781402003912, Pages: 532. 